\title{
LA VULNERACIÓN DEL IUS IN OFFICIUM \\ EN LA APLICACIÓN DE LOS ARTÍCULOS 150 DEL REGLAMENTO DEL CONGRESO DE LOS DIPUTADOS Y 129 DEL REGLAMENTO DEL SENADO'
} The infringement of ius in officium in the application
of the articles 150 RCD and 129 RS

\author{
M. a PILAR GARCÍA ROCHA \\ Universidad de Murcia \\ pilar.garcia.rocha@um.es
}

Cómo citar/Citation

García Rocha, M. a P. (2020).

La vulneración del ius in officium en la aplicación de los arts. 150 RCD y 129 RS.

Revista de Estudios Políticos, 187, 209-231.

doi: https://doi.org/10.18042/cepc/rep.187.08

\section{Resumen}

En este artículo se analiza uno de los mayores riesgos de la aplicación del procedimiento legislativo en lectura única: la eventual violación del ius in officium del parlamentario. Se procede a examinar las dos posibles quiebras de este derecho fundamental estudiando, de una parte, el derecho a no tramitar una iniciativa legislativa en lectura única si no concurre alguno de los presupuestos habilitantes establecidos en los arts. 150 del Reglamento del Congreso y 129 del Reglamento del Senado; y de otra, el derecho a presentar enmiendas al articulado en esta vía procesal extraordinaria. Acometemos un riguroso examen de los rasgos esenciales de estos derechos y de las condiciones en las que puede tener lugar su eventual quiebra. Finalmente se pone de relieve la improcedente vinculación establecida en la reciente jurisprudencia

1 Este trabajo se ha realizado en el marco del proyecto «Reforma constitucional: dimensión institucional y territorial»(20639/JLI/18), financiado por la Fundación Séneca-Agencia de Ciencia y Tecnología de la Región de Murcia a través de la convocatoria Jóvenes Líderes en Investigación del Subprograma de Apoyo y Liderazgo Científico y la Transición a la Investigación Independiente (Programa Fomento de la Investigación Científica y Técnica 2018). 
del Tribunal Constitucional entre las mayorías parlamentarias con las que se decide este tipo de tramitación y la posibilidad de presentar enmiendas al articulado.

\section{Palabras clave}

Lectura única; quiebra del ius in officium; procedimiento legislativo adecuado; enmiendas al articulado; mayorías parlamentarias.

\section{Abstract}

In this article we analyse one of the most complex aspects of the legal framework in single readings: the infringement of MPs ius in officium in the process of a legislative initiative using this abbreviated procedure. We will examine two possible violations of this fundamental right, studying, on one hand, the right not to process a legislative initiative in a single reading if some or any of the enabling circumstances established in articles 150 of the Rules of Congress of Deputies and 129 of the Rules of the Senate have not been met, and also, the right to present amendments to the article in this extraordinary process. In relation to this second case, we undertake a rigorous examination of the essential features of this right and the conditions in which its eventual violation may take place. Finally, we will highlight the inappropriate link established in the recent jurisprudence of the Constitutional Tribunal between parliamentary majorities which decide this type of process and the possibility of presenting amendments to the articles.

\section{Keywords}

Single reading; infringement of ius in officium; adequate legislative procedures; amendments to the article; parliamentary majorities. 


\section{SUMARIO}

I. LA CONFIGURACIÓN GENERAL DEL IUS IN OFFICIUM DEL PARLAMENTARIO Y SU PROYECCIÓN SOBRE EL PROCEDIMIENTO LEGISLATIVO. II. LAS DOS POSIBLES QUIEBRAS DEL IUS IN OFFICIUM EN LA TRAMITACIÓN DE LAS INICIATIVAS EN LECTURA ÚNICA: 1. Primera dimensión: el derecho del parlamentario al procedimiento legislativo adecuado. 2. Segunda dimensión: el derecho del parlamentario a presentar enmiendas al articulado en los procedimientos en lectura única: 2.1. Los rasgos esenciales del derecho a la enmienda. 2.2. Las condiciones de su eventual quiebra en los procedimientos legislativos en lectura única. 2.3. La improcedente vinculación entre las mayorías con las que se decide este tipo de tramitación y la posibilidad de presentar enmiendas al articulado. III. UNA PROPUESTA DE MODIFICACIÓN DE LOS USOS PARLAMENTARIOS. BIBLIOGRAFÍA.

\section{LA CONFIGURACIÓN GENERAL DEL IUS IN OFFICIUM DEL PARLAMENTARIO Y SU PROYECCIÓN SOBRE EL PROCEDIMIENTO LEGISLATIVO}

Como es bien conocido, el llamado ius in officium del parlamentario que recoge el art. 23.2 de la Constitución Española (CE) ha sido objeto de numerosos estudios por parte de la doctrina (Alexy, 2014; Arruego, 2005; García Roca, 1999; Fossas, 1993; Jiménez, 1997; Pulido, 1992; Schmitt, 2008; Biglino Campos, 1993), y desarrollado ampliamente por la jurisprudencia del Tribunal Constitucional (SSTC 161/1988, de 20 de septiembre; $181 / 1989$, de 3 de noviembre; 205/1990, de 13 de diciembre; 107/2001, de 23 de abril; 177/2002, de 14 de octubre; 361/2006, de 18 de diciembre), lo que ha ido configurando y concretando sus contenidos esenciales durante estas décadas (Torres, 1998; Cobreros, 1991).

De todas esas aportaciones doctrinales y jurisprudenciales señalamos en los siguientes párrafos solo aquellas que interesan a nuestro análisis, esto es, aquellas que tienen que ver con la proyección que este derecho fundamental de los parlamentarios tenga sobre su participación en los procedimientos legislativos en general, y sobre el procedimiento legislativo abreviado en lectura única en particular. Así debemos destacar:

En primer lugar, que el derecho a «acceder en condiciones de igualdad a las funciones y cargos públicos con los requisitos que señalen las leyes» que establece el art. 23.2 CE, incluye no solo el derecho al acceso a los cargos 
públicos representativos, sino también el derecho a mantenerse en ellos y a desempeñarlos en los términos en que la ley señale en cada caso. No pudiendo el legislador, en la concreción de tales desarrollos, vaciar de contenido esencial la función del representante, estorbarla o dificultarla mediante obstáculos artificiosos, o colocar a unos representantes y a otros en discriminatoria posición jurídica, puesto que «si es necesario que el órgano representativo decida siempre en el sentido querido por la mayoría, no lo es menos que se deba colocar a todos los votantes en iguales condiciones de acceso al conocimiento de los asuntos y de participación en los distintos estadios del proceso de decisión» (STC 32/1985, de 20 de septiembre).

En segundo lugar, este derecho se cimenta, a su vez, en lo dispuesto por el art. $1 \mathrm{CE}$, esto es, en la existencia de una democracia plural y una forma de gobierno parlamentaria. Lo que significa que la formación de la voluntad de las Cámaras debe responder siempre al principio mayoritario, pero sin olvidar la obligada protección de los derechos de las minorías. Así, el ejercicio de la función legislativa por parte de los representantes de los ciudadanos constituye "la máxima expresión del ejercicio de la soberanía popular en el Estado democrático", resultando, pues, el normal desempeño de esta principalísima función del parlamentario y de los derechos y deberes que la acompañan «una manifestación constitucionalmente relevante del ius in officium del representante» (STC 10/2016, de 1 de febrero) ${ }^{2}$.

En tercer lugar, señalar, además, que el contenido del derecho del parlamentario recogido en el art. 23.2 CE se encuentra en íntima conexión con el apartado primero que le precede: «Los ciudadanos tienen el derecho a participar en los asuntos públicos, directamente o por medio de representantes, libremente elegidos en elecciones periódicas por sufragio universal». De modo que son "primordialmente los representantes políticos de los ciudadanos quienes dan efectividad a su derecho a participar en los asuntos públicos. De suerte que el derecho del art. 23.2 CE, así como, indirectamente, el que el art. 23.1 reconoce a los ciudadanos, quedaría vacío de contenido, o sería ineficaz, si el representante político se viese privado del mismo o perturbado en su ejercicio» (SSTC 96/2019, de 15 de julio; 10/2018, de 5 de febrero; 38/1999, de 2 de marzo; 107/2001, de 23 de abril; 177/2002, de 14 de octubre; 202/2014, de 15 de diciembre; 40/2003, de 17 de febrero). Como ha destacado acertadamente la doctrina más autorizada (Fossas, 1993: 69) «la conexión entre los dos apartados del art. 23 CE tiene [...] una importancia decisiva en la doctrina constitucional del derecho de participación política y, consecuentemente, en la

2 Véase sobre el particular, García-Escudero (2007: 27 y ss., 2009: 79 y ss.); García Roca (2014: 24 y ss.); Gómez Lugo (2019: 389 y ss.). 
configuración del derecho de acceso a los cargos públicos, puesto que en ella [...] el Tribunal Constitucional ha encontrado los cimientos para iniciar la construcción de un verdadero status del representante». Así, pues, prácticamente cualquier vulneración del art. 23.2 CE lo será también —y a su travésdel art. 23.1 CE.

En cuarto lugar, advertimos que de forma inequívoca se desprende de la literalidad del inciso final del propio art. 23.2 CE que estamos ante un derecho de configuración legal. Corresponde, pues, a la ley, en este caso a los reglamentos parlamentarios, "ordenar los derechos y facultades que corresponden a los distintos cargos públicos, pasando aquellos, en virtud de su creación legal, a quedar integrados en el estatus propio de cada cargo, con la consecuencia de que sus titulares podrán defender, al amparo del art. 23.2 CE, el ius in officium que consideren ilegítimamente constreñido o ignorado por los actos del poder público, incluidos los provenientes del propio órgano en el que se integran» (SSTC 27/2000, de 31 de enero; 36/2014, de 27 de febrero; 224/2016, de 19 de diciembre). Su calificación, pues, como derecho de configuración legal «significa lisa y llanamente que se habilita al legislador, desde la propia Constitución, para delimitar el ámbito del derecho, sin mellar su contenido esencial» (STC 225/1992, de 14 de diciembre) ${ }^{3}$, esto es, el reglamento parlamentario no puede conculcar «el núcleo de los derechos y facultades de los representantes o, en otros términos, a su estatuto constitucionalmente relevante» (STC 110/2019, de 2 de octubre).

Y ese margen de libertad que la Constitución otorga al reglamento parlamentario para regular el ejercicio de este derecho y, muy en particular, su proyección sobre la participación de los representantes en los procedimientos legislativos es —en conexión con la tantas veces aludida remisión in toto a los reglamentos parlamentarios del régimen de los procedimientos legislativos recogida en el art. 89.1 CE- muy amplio.

3 A este respecto, cabe distinguir, siguiendo a Fossas (1993: 132-133), entre los planos de legalidad y constitucionalidad de este derecho fundamental. Así, afirma este autor que «en el plano de la legalidad se mueve el derecho material de acceso y ejercicio del cargo, porque sin los requisitos que establece la norma infraconstitucional no puede ejercerse tal derecho. En el plano de la constitucionalidad se mueve el derecho fundamental a la igualdad en el totum acceso/permanencia/ejercicio que garantiza a todo ciudadano unos requisitos legales no discriminatorios y pone a su disposición los mecanismos contra los actos de los poderes públicos (de creación, aplicación e interpretación de los requisitos) que conculquen la integridad del objeto del derecho fundamental. El mecanismo por excelencia será el que abre la posibilidad de llevar a cabo una acción impugnatoria de la actuación pública contraria al derecho a la igualdad y permite reestablecer su integridad». 
No obstante, se trata de una habilitación sujeta, lógicamente, a límites constitucionales: las normas reglamentarias que regulen los requisitos y condiciones de ejercicio de este derecho, así como sus actos de aplicación, son revisables por el Tribunal Constitucional «no solo por la quiebra de la igualdad, sino por cualquier otro género de inadecuación a su contenido esencial, [...] pues, de lo contrario, los derechos fundamentales de configuración legal quedarían degradados al plano de la legalidad ordinaria»(STC 24/1990, de 15 de febrero). De ahí el carácter decisivo, a nuestros efectos, del régimen establecido por los arts. 150 RCD y 129 RS, así como de su correcta interpretación y aplicación por los órganos rectores de ambas Cámaras.

Pese a todo ello, en quinto lugar seńalamos que no cualquier acto de los órganos parlamentarios que infrinja la legalidad del ius in officium resultará lesivo del derecho fundamental, «pues solo poseen relevancia constitucional a estos efectos los derechos o facultades atribuidos al representante que pertenezcan al núcleo de su función representativa parlamentaria» (STC 38/1999, de 22 de marzo). Dicho de otro modo, la Constitución en su art. 23.2 no otorga la condición de derecho fundamental —accionable, por tanto, en amparo ante el Tribunal Constitucional- a todos los derechos y facultades del estatuto legal del parlamentario, «sino tan solo aquellos que pudiéramos considerar pertenecientes al núcleo de la función representativa, como son, principalmente, los que tienen relación directa con el ejercicio de las potestades legislativas y de control de la acción del Gobierno» (STC 109/2016, de 7 de junio). Además, la apreciación de la vulneración del derecho fundamental por infracción de la legalidad parlamentaria y la afectación o no del núcleo esencial de la función representativa debe ser valorada caso por caso ${ }^{4}$.

¿Y cuáles son, entonces, los contenidos esenciales de este derecho fundamental?, ¿esos elementos nucleares de la función representativa protegidos por el art. 23.2 CE en relación con la participación de los parlamentarios en los procedimientos legislativos? La jurisprudencia constitucional ha reconocido alguno más ${ }^{5}$, pero por lo que hace al objeto de nuestro análisis, dos son los

4 Véase, al respecto, STC 119/2011, de 5 de julio: «La aplicación de esta doctrina exige, para apreciar la vulneración aducida por los recurrentes, en primer lugar, examinar si ha existido una infracción de la legalidad parlamentaria para, posteriormente, analizar si, en su caso, dicha infracción, además, ha afectado al núcleo de su función representativa».

5 Véase, el derecho a la iniciativa legislativa, a la participación en los debates y el derecho a votar los acuerdos que adopten las Cámaras. Sobre el particular, STC 119/2011, de 5 de julio: «El ius in officium afecta a toda una seria de situaciones de los parlamentarios en las que los órganos de las Cámaras deben respetar la función representativa no por tratarse de facultades meramente subjetivas de quienes desarrollan esa función, sino 
contenidos relevantes a destacar: el derecho al procedimiento legislativo adecuado y el derecho a presentar — debatir y votar- enmiendas ${ }^{6}$.

Así, por un lado, el Tribunal Constitucional ha afirmado —en pocas ocasiones, pero muy claramente- que «en el ejercicio de la función legislativa a través del procedimiento parlamentario reglamentariamente establecido para la concreta iniciativa objeto de tramitación y el desempeño en el mismo de los derechos y facultades que lo acompańan constituye, en principio, una manifestación relevante del ius in officium del representante», por lo que debe considerarse perteneciente "al núcleo duro de su función representativa que los proyectos y proposiciones legislativas [...] se tramiten con los requisitos y a través de los procedimientos establecidos en la Constitución Española y en el Reglamento del Congreso de los Diputados» (STC 118/1999, de 28 de junio; y ATC 85/2006, de 15 de marzo). Y, por otro lado, y de manera mucho más reiterada, también ha dispuesto que el derecho de enmienda «no es un mero derecho reglamentario, sino un auténtico contenido central de su derecho de participación del art. 23.2 CE [...]» (SSTC 119/2011, de 5 de julio; 96/2019, de 15 de julio).

Es por todo ello que, a continuación, nos dedicaremos al análisis de estas dos dimensiones del núcleo esencial del ius in officium del parlamentario, en la medida en que la vulneración de cualquiera de ambos contenidos sí podría llevarnos a un escenario de inconstitucionalidad y nulidad radical de la ley aprobada en lectura única. En otras palabras, las quiebras del contenido esencial constitucionalmente garantizado por el art. 23.2 CE pueden tener lugar bien porque los órganos de las Cámaras decidan tramitar una iniciativa legislativa por la vía del procedimiento abreviado en lectura única sin que

como facultades que lo que permiten es ejercer correctamente a los representantes populares dicha representación participando en la función legislativa. Esto impone hacer posible la presentación de propuestas legislativas, la discusión en el debate parlamentario público [...], interviniendo en la mejora de los textos mediante la introducción de enmiendas y respetar su derecho a expresar su posición mediante el derecho a voto".

6 No ocurriría tal vulneración en la situación contraria, esto es, en el caso de que pudiera proceder el trámite en lectura única al concurrir alguno de los presupuestos habilitantes y alguna de las Cámaras optara por el procedimiento legislativo ordinario completo: en primer lugar, por el carácter potestativo que tiene la tramitación en lectura única (las Cámaras "podrán acordar» esa tramitación abreviada, según la literalidad de los artículos 150 RCD y 129 RS); y en segundo lugar, y en todo caso, porque a través de la vía del procedimiento legislativo ordinario, si bien se podrían llevar a cabo actos parlamentarios prescindibles o redundantes, no estaríamos nunca ante una limitación de facultades de los parlamentarios. 
concurran los presupuestos habilitantes establecidos en los reglamentos del Congreso y del Senado, por vulneración del derecho al procedimiento legislativo reglamentariamente adecuado, por no conceder apertura para la tramitación de enmiendas - en el Congreso de los Diputados-, o por vulneración del derecho a la enmienda de los parlamentarios al inadmitir indebidamente alguna enmienda cuando una iniciativa vaya a tramitar en lectura única.

En último lugar, hemos de tener siempre presente que la tanto la vulneración del derecho al procedimiento adecuado, como la vulneración del derecho a presentar y tramitar la enmienda, para que derivaran en inconstitucionalidad y nulidad de la ley correspondiente habrían de haber tenido un impacto tal en el procedimiento legislativo en cuestión que se hubiera visto alterado «de modo sustancial el proceso de formación de la voluntad en el seno de las Cámaras» (STC 103/2008, de 11 de septiembre. Véase, en el mismo sentido, SSTC 136/2011, de 13 de septiembre; 44/2015, de 5 de marzo), que es, en último término, lo que el art. 23.2 CE y sus concordantes en la propia Constitución y en los reglamentos parlamentarios pretenden proteger. En recientes palabras del propio Tribunal Constitucional, estas vulneraciones solo tendrán «relevancia constitucional cuando su alcance sea de tal magnitud que haya alterado, no de cualquier manera, sino de forma sustancial, el proceso de formación de la voluntad de una Cámara, habiendo afectado, en consecuencia, al ejercicio de la función representativa inherente al estatuto del parlamentario» (STC 143/2016, de 19 de septiembre).

\section{LAS DOS POSIBLES QUIEBRAS DEL IUS IN OFFICIUM EN LA TRAMITACIÓN DE LAS INICIATIVAS EN LECTURA ÚNICA}

\section{PRIMERA DIMENSIÓN: EL DERECHO DEL PARLAMENTARIO AL PROCEDIMIENTO LEGISLATIVO ADECUADO}

Como hemos afirmado líneas atrás, el derecho del parlamentario a que las iniciativas legislativas se tramiten por el procedimiento adecuado, entendiendo como tal en este caso el procedimiento que decidan la Mesa y el Pleno (oída la Junta de Portavoces) conforme a los supuestos habilitantes establecidos en el reglamento - no necesariamente el que pudiera pretender el sujeto que presenta la iniciativa (Arce, 1996: 227) 7 - es uno de los contenidos

7 «La calificación de los escritos y documentos parlamentarios por los órganos rectores de las Cámaras solo podría alterar la que el propio autor del escrito o documento haya hecho cuando efectivamente pueda apoyar esta rectificación en algún precepto 
relevantes que constituyen el núcleo esencial del derecho fundamental ex art. 23.2 $\mathrm{CE}^{8}$. Reconocimiento expreso en los pronunciamientos de nuestro Tribunal Constitucional y así ha sido recogido también por la doctrina mayoritaria ${ }^{9}$, que ha venido a destacar, además, la triple dimensión de este derecho en su concepción más amplia: el derecho a la calificación de la iniciativa, el derecho a su admisión a trámite y el derecho a una tramitación por el cauce procedimental adecuado, todo ello, lógicamente, conforme al reglamento de la Cámara ${ }^{10}$.

Evidentemente, calificación y admisión a trámite de la iniciativa son actos íntimamente conectados que condicionan de manera decisiva, a su vez, la decisión de vehicular la iniciativa presentada por un procedimiento legislativo u otro ${ }^{11}$. Asimismo, se ha señalado que este vicio procedimental debe ser

reglamentario (STC 99/1987, de 11 de junio). Esta primera regla es, me parece, difícilmente impugnable, por cuanto el derecho a que se proceda de diputados y grupos no comprende el derecho al procedimiento que se pretenda, sino únicamente el derecho al procedimiento reglamentariamente adecuado, de modo que, por eso mismo, cuando nada en el reglamento parlamentario indique que el propuesto por el autor del escrito a tramitar no es el procedimiento adecuado no habrá posibilidad de seleccionar otro en su lugar».

8 Véase, García-Escudero (2012: 58 y ss., 2011:14 y ss.).

9 Véase, por todos, Gómez (2019: 415-416): «Efectivamente, la inobservancia de los límites procedimentales, en general, y del procedimiento adecuado establecido, en particular, puede ser constitutiva de un vicio in procedendo, pero también de una lesión del derecho de acceso a cargo representativo del artículo 23.2 CE en su vertiente del derecho a tramitar las iniciativas conforme al procedimiento previsto por las normas constitucionales y el reglamento parlamentario».

10 El Tribunal Constitucional ha insistido muy recientemente en que el derecho al procedimiento adecuado no equivale, ni mucho menos, al derecho al procedimiento solicitado por quien presenta la iniciativa legislativa — ni aun en el caso de que existiera mayoría parlamentaria favorable en el Pleno- «sin examen ni control previo alguno» por la Mesa de la Cámara, conforme a las condiciones establecidas en el artículo 150 RCD (STC 110/2019, de 2 de octubre).

11 Véase, Gómez (2009: 13): «La justificación de esta extensión del derecho a tramitar iniciativas legislativas conforma al procedimiento adecuado incorporando estas atribuciones es obvia: para dotar de efectividad al mismo, y no vaciarlo de contenido, es necesario que la Mesa califique el texto, lo admita a trámite y decida el procedimiento conforme al cual lo tramitará. Se trata de actos conexionados en el sentido de que para decidir la tramitación previamente se ha debido calificar la propuesta y admitirla a trámite. Asimismo, para garantizar la efectividad del derecho la Mesa debe llevar a cabo un correcto desempeńo, y no extralimitarse, de sus potestades al calificar, admitir y decidir la tramitación. Es precisamente durante esta intervención del órgano de 
determinante para la conformación de la voluntad de la Cámara ${ }^{12}$, si lo que se pretende es la declaración de nulidad del mandato legislativo aprobado por el Parlamento a través de un cauce improcedente ${ }^{13}$. Extremo este que deberá haber sido denunciado ya en sede parlamentaria por los interesados, a quienes, además, les corresponde la carga de la prueba, lo que impide en muchos casos el éxito de tales pretensiones.

De este modo, en la mayoría de las ocasiones el Tribunal Constitucional ha entendido que no son decisivas para la correcta conformación de la voluntad de las Cámaras las irregularidades relativas al procedimiento legislativo que le han sido alegadas. Así, por ejemplo, en la STC 176/2011, de 8 de noviembre, dictaminó como no relevante que la toma de la decisión relativa a la tramitación de un proyecto de ley orgánica en lectura única se adoptara en una sesión plenaria de carácter extraordinario (SSTC 136/2011, de 13 de septiembre; 102/2012, de 8 de mayo; 209/2012, de 14 de noviembre; 36/2013, de 14 de febrero).

Por el contrario, encontramos muy pocos ejemplos en la jurisprudencia del Tribunal Constitucional acerca de vicios in procedendo vinculados con esta concreta vertiente del ius in officium que hayan dado lugar a la declaración de inconstitucionalidad de la norma afectada. Tal fue el caso - excepcional pero muy relevante- de la STC 10/2018, de 5 de febrero, que estimó el Recurso de Amparo 4304-2017 interpuesto por diputados del Grupo Socialista del Parlamento de Cataluña contra la decisión de la Mesa de la Cámara de inadmitir la solicitud del dictamen del Consejo de Garantías Estatutarias sobre la Proposición de Ley del Referéndum de Autodeterminación.

El Tribunal Constitucional en este caso entendió que «la posibilidad de pedir dicho dictamen no puede ser suprimida por la Cámara sin merma de la integridad del propio procedimiento legislativo y a la vez de los derechos de los representantes a ejercer esta concreta facultad que la ley les confiere y que se incorpora a su estatus jurídico-constitucional». En consecuencia, el Tribunal

dirección cuando puede plantearse la trasgresión del derecho por parte del poder público», y Fernández (2018: 2017 y ss.).

12 Véase, STC 44/2015, de 5 de marzo: «La existencia de un determinado defecto en la tramitación parlamentaria de una norma sólo tendrá trascendencia si se hubiere privado a las Cámaras de un elemento de juicio necesario para su decisión, siendo imprescindible que el citado defecto se hubiese denunciado ante las mismas Cámaras».

13 El Tribunal Constitucional se ha referido muy claramente a esta cuestión en la STC 143/2016, de 19 de septiembre, en la que, en relación con la reducción de los plazos que lleva aparejada la declaración de urgencia del procedimiento legislativo, afirmó que «sin perjuicio de la necesidad de que se expongan dichas circunstancias, resulta necesario acreditar que dicha reducción afectó esencialmente al proceso de la formación de la voluntad de los parlamentarios». 
declaró la vulneración del derecho reconocido en el art. 23.2 CE y la «nulidad del acuerdo de la Mesa del Parlamento de Cataluña de 6 de septiembre de 2017, que dispuso la inadmisión de la solicitud de dictamen del Consejo de Garantías Estatutarias previsto en los arts. 16 y 23 de la Ley del Consejo de Garantías Estatutarias, así como la nulidad del acuerdo de esa misma fecha, desestimatorio de la reconsideración».

Nosotros entendemos que este reciente pronunciamiento del Alto Tribunal podría marcar un hito relevante, a los efectos que aquí interesan, siempre y cuando se atendiera desde la jurisprudencia constitucional que la Mesa —oída la Junta de Portavoces_- y el Pleno no pueden adoptar la decisión de someter una iniciativa legislativa al trámite en lectura única por el solo hecho de que exista acuerdo mayoritario en la Cámara a tal efecto ${ }^{14}$. Y que, por el contrario, solo procederá dar apertura a este procedimiento abreviado para la tramitación de leyes de naturaleza pactada o de iniciativas legislativas que verdaderamente posean una formulación suficientemente sencilla como para poder ser debatidas y votadas — con las correspondientes enmiendas, en su casodirectamente por el Pleno con todas las garantías para los parlamentarios, sin que sea necesario su trámite en comisión. Esta es la categorización de los presupuestos habilitantes de la lectura única que este trabajo defiende y en consecuencia, aquellos casos en los que no concurriendo tales circunstancias se hubiera acordado apertura del trámite en lectura única, procedería la declaración de inconstitucionalidad por lesión del ius in officium del parlamentario en su faz de derecho al procedimiento adecuado.

A nuestro juicio, más allá de que se proceda a la apertura o no del plazo para la presentación de enmiendas - extremo al que nos referiremos a continuación-, la sola omisión de la fase de comisión íntegramente (informe de la ponencia, debate en comisión y dictamen de la comisión) ya es, sin duda, una alteración del cauce legislativo ordinario que condiciona terminantemente el resultado de la decisión normativa de las Cámaras, tanto o más que la omisión del dictamen del Consejo de Garantías Estatutarias en el caso descrito de la STC 10/2018, de 5 de febrero. Y, si pudiera no serlo en todos los casos, lo que sí procedería, desde luego, es que el Tribunal acogiera la presunción iuris tantum de que, en principio, tal omisión es siempre relevante para la correcta formación de la voluntad de la Cámara e invertir de ese modo la carga de la prueba, que recaería sobre quien pretendiera alegar su irrelevancia. Encontraría, además, de este modo el Tribunal un punto de encuentro congruente con otra afirmación que viene realizando en relación con el modo restrictivo en que se

14 Véase, sobre el particular, la SSTC 45/2019, de 27 de marzo; 96/2019, de 15 de julio; $110 / 2019$ de 2 de octubre. 
deben interpretar las decisiones de los órganos parlamentarios cuando éstas limiten el ejercicio del ius in oficium.

Así, el máximo intérprete de la Constitución ha afirmado en reiteradas ocasiones — varias de ellas, además, muy recientes - que «el hecho de que mediante las decisiones de los órganos parlamentarios pueda verse afectado el ejercicio de funciones representativas impone a estos una interpretación restrictiva de todas aquellas normas que puedan suponer una limitación al ejercicio de aquellos derechos o atribuciones que integran el estatus constitucionalmente relevante del representante público y el deber de motivar las razones de su aplicación, so pena, no solo de vulnerar el derecho fundamental del representante de los ciudadanos a ejercer su cargo —art. 23.2 CE—, sino también de infringir el de estos a participar en los asuntos públicos — art. 23.1 CE— (SSTC 143/2016, de 19 de septiembre; 361/2006, de 18 de diciembre; 1/2015, de 19 de enero; 23/2015, de 16 de febrero).

\section{SEGUNDA DIMENSIÓN: EL DERECHO DEL PARLAMENTARIO A PRESENTAR ENMIENDAS AL ARTICULADO EN LOS PROCEDIMIENTOS EN LECTURA ÚNICA}

\subsection{Los rasgos esenciales del derecho a la enmienda}

El derecho a presentar enmiendas de diputados y senadores en la tramitación de cualquier iniciativa legislativa, según jurisprudencia consolidada del Tribunal Constitucional, "pertenece al núcleo duro de su función representativa", constituyendo así «una manifestación constitucionalmente relevante del ius in offcium del representante» (STC 38/1990, de 1 de marzo). Tesis que, además, ha sido asumida plenamente y de modo pacífico por la doctrina más autorizada (Biglino Campos, 1993: 53 y ss.; García-Escudero, 2012: 59-60). De modo muy sintético, los rasgos esenciales del derecho a la enmienda como elemento nuclear del ius in officium que podemos extraer de esa doctrina constitucional, a los efectos que aquí son relevantes, son los exponemos a continuación.

En primer lugar, el derecho de enmienda es «inherente a la potestad legislativa de las Cámaras», pues su capacidad para dictar la ley «no puede quedar reducida a una mera ratificación o veto del texto propuesto por el autor de la iniciativa legislativa", en la medida en que ese derecho de enmienda cumple «la relevante función de garantizar la participación de los diputados y grupos parlamentarios en el proceso de elaboración de la ley»y, por tanto, «en la formación de la voluntad de la Cámara» (SSTC 136/2011, de 13 de septiembre; 204/2011, de 15 de diciembre).

Además de ello, en segundo lugar, el derecho a presentar enmiendas es un «cauce al servicio de la función representativa de todo Parlamento», puesto 
que cumple asimismo «la muy importante función de permitir a los ciudadanos conocer la postura de sus representantes respecto de una determinada iniciativa legislativa, así como las alternativas o modificaciones que puedan proponer en relación con la misma, y extraer sus propias conclusiones acerca de cómo aquellos asumen o se separan de sus respectivos programas electorales» (STC 124/1995, de 18 de julio). Se pone así de manifiesto que este derecho «sirve a la naturaleza democrática del procedimiento legislativo y al valor del pluralismo político (STC 44/1995, de 13 de febrero), permitiendo canalizar la participación de las minorías parlamentarias.

Consecuentemente, en tercer y último término, el derecho de enmienda «entronca directamente» de este modo "con el derecho de participación política reconocido en el art. 23.2 CE, formando parte integrante del contenido del ius in officium de los parlamentarios que el citado derecho fundamental por sí mismo garantiza» (STC 119/2011, de 5 de julio). Este precepto constitucional remite el régimen de los requisitos y condiciones de ejercicio de ese derecho y de todos sus contenidos — por tanto, también el régimen del derecho de enmienda-, al reglamento parlamentario. Sin embargo, tales normas parlamentarias no pueden desconocer que el derecho de enmienda es «elemento integrante del contenido central del derecho fundamental al ejercicio del cargo parlamentario», cosa que sucedería si «lo vaciaran de contenido, lo sometieran a limitaciones que lo hacen impracticable o dificultan su ejercicio más allá de lo razonable, lo desnaturalizan o resulta irreconocible como tal derecho», pues en tales supuestos el reglamento y/o los órganos parlamentarios que lo aplican estarían «invadiendo el contenido constitucional indisponible» del derecho de enmienda (SSTC 204/2004, de 18 de noviembre; 196/1987, de 11 de diciembre; 161/1987, de 27 de octubre).

Así las cosas, debemos, por tanto, plantearnos cómo se proyecta esta doctrina sobre regulación reglamentaria y la aplicación que de la misma articulan la Mesa y el Pleno en los procedimientos legislativos sometidos a lectura única. Entendiendo que nos referimos ahora ya a procedimientos legislativos que se han abierto en lectura única tras una correcta decisión de los órganos parlamentarios correspondientes y ajustada a las condiciones que establecen los reglamentos parlamentarios. Esto es, situados ya en un supuesto en el que no se ha vulnerado el derecho a tramitar una iniciativa por el procedimiento adecuado, procede analizar si dentro de tal procedimiento cabe la vulneración del derecho a la enmienda y, por tanto, del ius in officium del parlamentario.

\subsection{Las condiciones de su eventual quiebra en los procedimientos legislativos en lectura única}

A tal efecto, debemos aquí distinguir entre el régimen establecido por el Reglamento del Senado y el Reglamento del Congreso de los Diputados, pues 
nos llevan a escenarios absolutamente diferentes. Que los senadores no puedan presentar enmiendas al articulado de un texto que la Cámara Alta ha decidido tramitar en lectura única, más allá de que pueda parecernos una mejor o peor opción de política legislativa, no contraviene el ius in officium del parlamentario por cuanto que la configuración legal del mismo permite al Reglamento del Senado, según la jurisprudencia constitucional (STC 238/2012, de 13 de diciembre), limitar el derecho de enmienda de los senadores a la posibilidad de presentar propuestas de veto al texto aprobado por el Congreso de los Diputados. Así lo dispone taxativamente, como ya hemos indicado, el art. 129.3 RS. A la vista de los datos de la práctica, se puede advertir claramente cómo esta prohibición provoca que en el Senado se opte mucho menos frecuentemente por seguir el procedimiento legislativo en lectura única, incluso en aquellas tramitaciones ya iniciadas a través de ese procedimiento abreviado en el Congreso de los Diputados ${ }^{15}$.

Por el contrario, en el Congreso de los Diputados la situación es bien distinta, por cuanto que su Reglamento no recoge prohibición expresa de enmiendas parciales al texto de la iniciativa cuando esta es tramitada en lectura única. Partiendo de ese silencio reglamentario, debemos, a su vez, según nuestro criterio, distinguir dos supuestos:

Cuando el procedimiento en lectura única hubiera procedido porque la naturaleza de la iniciativa a tramitar lo aconseje, esto es, según la tesis aquí defendida, porque la iniciativa tenga la condición de ley paccionada a ratificar por las Cortes Generales, no solo no habría lesión del ius in officium del diputado en el caso de que la Mesa, separándose del uso parlamentario habitual, no abriera plazo de presentación de enmiendas al articulado, sino que, a nuestro juicio, resultaría completamente improcedente esta apertura precisamente por la condición pactada de la norma que tramitar.

A reforzar nuestra postura viene la ya citada STC 27/2000, de 31 de enero, que determinó, en relación con los proyectos de ley que establecen las aportaciones de las Diputaciones Forales a la Hacienda General del País Vasco y los que fijan la metodología para su determinación por períodos plurianuales, la constitucionalidad de su tramitación en lectura única y sin posibilidad de

15 Sirva, tan solo a modo de ejemplo, el caso de la Ley 5/2017, de 29 de septiembre, por la que se modifica la Ley 17/2006, de 5 de junio, de la radio y la televisión de titularidad estatal, para recuperar la independencia de la Corporación RTVE y el pluralismo en la elección parlamentaria de sus órganos. (BOE, núm. 236, de 30 de septiembre de 2017), tramitada por el procedimiento de lectura única en el Congreso de los Diputados, y no así en el Senado. Véase la tramitación de las leyes aprobadas en lectura única en: http://bit.ly/2SdCzFJ. 
presentación de enmiendas al articulado por su condición de «leyes de aprobación", es decir, de leyes "que incorporan unos contenidos ya pactados». En estos casos, se cumple suficientemente con las exigencias del art. 23.2 CE por vía de la participación de los diputados y los grupos parlamentarios «tanto en los trámites preliminares como en el momento mismo del debate y votación final sobre la aprobación o el rechazo del proyecto de ley».

A estos concretos supuestos entendemos que debería ir referida la afirmación que la STC 139/2017, de 29 de noviembre, hace sobre la posibilidad de que «excepcionalmente puedan existir supuestos de supresión o privación circunstancial u ocasional del derecho de enmienda, pero tal supresión o privación únicamente serán admisibles cuando estén dotadas de fundamento constitucional o puedan resultar justificadas en atención a la naturaleza o características de un determinado procedimiento legislativo, que conviertan en innecesario o superfluo el ejercicio del derecho de enmienda» ${ }^{16}$.

Por el contrario, cuando la tramitación por este procedimiento abreviado hubiera procedido en virtud del segundo de los supuestos habilitantes, esto es, por la simplicidad de formulación de la iniciativa legislativa en cuestión, sí podríamos estar ante una potencial quiebra del ius in officium de los diputados, bien porque la Mesa se apartara del uso parlamentario que se viene aplicando desde la primera tramitación en lectura única en la Cámara Baja - a cuya fuerza de obligar ya nos hemos referido ${ }^{17}$ - y no abriera trámite de presentación de enmiendas al articulado, bien porque, habiéndolo abierto, inadmitiera indebidamente alguna de las enmiendas presentadas ${ }^{18}$. Y ello siempre y

16 La cursiva es mía. Desafortunadamente, como veremos, el Tribunal Constitucional pretende referirse con esa afirmación a los casos en los que la decisión de abrir el trámite legislativo en lectura única se haya adoptado por unanimidad de los miembros del Pleno.

17 STC 44/2015, de 5 de marzo: «Estamos en presencia de una práctica [...] que ha sido admitida por la Cámara al considerar que se ajusta al Reglamento y que es respetuosa con el artículo 23.2 CE, sin que vulnere precepto ni principio constitucional alguno. Antes, al contrario, de aceptarse el criterio postulado por los recurrentes se habría producido una violación del ius in officium de quienes proponían las enmiendas y, por tanto, del derecho fundamental contenido en el artículo 23.2 CE, al haberse alterado lo que pacíficamente había sido admitido para todos los grupos en anteriores ocasiones». Véase al respecto Fernández (2018: 241).

18 La reciente STC 45/2019, de 27 de marzo, recogiendo la doctrina ya establecida en otros pronunciamientos anteriores, ha recordado el silencio de los reglamentos parlamentarios en relación con la posibilidad de presentar enmiendas en el procedimiento legislativo en lectura única «no significa que ese trámite se excluya, ya que es una fase preceptiva y necesaria del procedimiento legislativo». 
cuando esa limitación al derecho de enmienda hubiera afectado sustancialmente a la correcta formación de la voluntad de la Cámara, en la medida en que la participación pretendida por el diputado no se hubiera podido vehicular de otro modo en las distintas fases del procedimiento legislativo, por lo que, lógicamente, la apreciación de esta quiebra del derecho fundamental recogido en el art. 23.2 CE habría de realizarse caso por caso.

Así lo ha afirmado el Tribunal Constitucional en reiteradas ocasiones: «Las consecuencias que se asocian a la adopción del procedimiento de lectura única, y que tienen que ver con los límites que se introducen en el debate parlamentario de la ley, así como en la posibilidad de introducir enmiendas [...] no hurtan automáticamente a las Cámaras las posibilidades de debate posterior como parecen pretender los recurrentes, sino que habrán de analizarse, caso por caso, si se acredita que la adopción de este tipo de procedimiento alteró de algún modo el proceso de formación de la voluntad parlamentaria ${ }^{19}$. Estos son, pues, a nuestro parecer, los términos que delimitan las condiciones de una eventual quiebra del ius in officium de los parlamentarios por vulneración del derecho de enmienda. Sin embargo, como veremos a continuación, la jurisprudencia del Tribunal Constitucional ha transitado recientemente por senderos muy distintos.

\subsection{La improcedente vinculación entre las mayorías con las que se decide este tipo de tramitación y la posibilidad de presentar enmiendas al articulado}

En efecto, hasta el año 2017 el Tribunal Constitucional, si bien con una jurisprudencia vacilante y excesivamente laxa respecto del juicio de control de la concurrencia de las circunstancias habilitantes del procedimiento de lectura única, había venido manteniendo - progresivamente y de forma cada vez más nítida - la afirmación de que, como no podía ser de otro modo, tales presupuestos habilitantes tenían una configuración reglamentaria que no quedaba vinculada al mayor o menor consenso que, respecto de su concurrencia, pudiera existir entre los diferentes grupos parlamentarios de las Cámaras.

Siguiendo la línea ya sugerida por otros pronunciamientos anteriores (SSTC 179/1989, de 2 de noviembre; 238/2012, de 13 de diciembre; 129/2013, de 4 de junio), la última sentencia que expone expresamente esta tesis es la STC 185/2016, de 3 de noviembre, en la que se afirma de forma nítida que «el consenso político que pudiera suscitar el proyecto o proposición de ley es algo totalmente ajeno a la concurrencia de los requisitos de simplicidad de formulación o naturaleza del texto normativo que permitan o aconsejen

19 STC 204/2011, de 15 de diciembre. Véase, en el mismo sentido, Gómez (2007: 12). 
su tramitación por el procedimiento en lectura única», por lo que «la decisión de recurrir a este procedimiento parlamentario ha de adoptarse por mayoría simple y no por unanimidad o mayoría cualificada alguna». Consecuentemente, el Tribunal nunca vinculó la posibilidad de introducir o no enmiendas en este tipo de procedimiento abreviado al mayor o menor consenso político sobre la procedencia de su tramitación sino, como venimos señalando, al impacto que la privación de ese derecho del parlamentario tuviera sobre la formación de la voluntad de la Cámara en cada caso.

Sin embargo, en la STC 139/2017, de 29 de noviembre ${ }^{20}$, sin renunciar al argumento de que lo constitucionalmente relevante para calibrar si existe o no vulneración del ius in officium del diputado es constatar hasta qué punto la supresión del derecho de enmienda ha afectado a la decisión legislativa final del Parlamento, ha establecido una presunción que vincula, injustificadamente a nuestro parecer, la adopción del acuerdo de tramitación en lectura única por unanimidad del Pleno con la improcedencia de abrir plazo de presentación de enmiendas al articulado.

Recoge de este modo el Alto Tribunal las constantes apelaciones de la doctrina mayoritaria al consenso político como eje sobre el que debe pivotar la implementación de este procedimiento abreviado. Valgan, por todos, las palabras de Gómez Lugo al respecto: «Resulta evidente que la elaboración de normas a través de este procedimiento especial producirá una reducción de las posibilidades de participación de la minoría en la tramitación legislativa [a través del derecho de enmienda], sobre todo su capacidad para manifestar públicamente sus discrepancias respecto a la legislación propuesta, de ahí que su aplicación deba reservarse a materias o textos de escasa trascendencia política, o ampliamente consensuados por las fuerzas politicas» ${ }^{21}$.

Concretamente, el Tribunal Constitucional ${ }^{22}$ en esta sentencia, apoyándose en su errónea interpretación de los presupuestos habilitantes de la lectura

20 Esta sentencia tiene como objeto el art. 135 del Reglamento del Parlamento de Cataluña, si bien la jurisprudencia que sienta en ella el Tribunal Constitucional es, no solo perfectamente trasladable al caso del Congreso de los Diputados, sino que en la misma se razona desde los parámetros propios del régimen estatal del procedimiento legislativo en lectura única.

21 Véase Gómez (2007: 12). La cursiva es mía.

22 En la sentencia el Tribunal sintetiza su jurisprudencia anterior en relación con los presupuestos habilitantes de la lectura única del siguiente modo: «Este tribunal tiene declarado que se trata de cláusulas o conceptos abiertos que confieren a los órganos de la Cámara un amplio margen de apreciación e interpretación en su aplicación, de modo que la valoración sobre la oportunidad de acudir a este tipo de procedimiento, así como sobre la concurrencia de los elementos de simplicidad del texto normativo o 
única y de su propia capacidad para controlar la concurrencia de los mismos, lo fía todo al grado de consenso político ${ }^{23}$ existente en la Cámara sobre si tramitar o no una iniciativa en lectura única, de forma que, en primer lugar, el derecho a presentar enmiendas deviene superfluo cuando la decisión abrir el procedimiento abreviado en lectura única ha sido adoptada por unanimidad en el Pleno — que en la práctica suele consistir en un mero asentimiento-, circunstancia que, además, no es necesario justificar — dice el Tribunal— por resultar obvia. Así, en dicho pronunciamiento se dice literalmente que «no cabe excluir, en principio, que la naturaleza o características de un determinado procedimiento legislativo puedan justificar también excepcionalmente una supresión o privación circunstancial u ocasional del derecho de enmienda, al devenir éste superfluo. Así, por ejemplo, sin necesidad de detenerse en más consideraciones por resultar ahora innecesarias, cuando sea precisa unanimidad de los diputados o grupos parlamentarios para activar una determinada iniciativa o procedimiento legislativo». Se refiere aquí, concretamente, el Tribunal Constitucional a los Parlamentos autonómicos cuyos reglamentos exigen unanimidad del Pleno para acudir al trámite en lectura única, pero en idéntica situación nos encontraríamos en el Congreso de los Diputados si se diera la circunstancia — no exigida por el reglamento - de que hubiera acuerdo unánime de los grupos parlamentarios para tramitar una iniciativa legislativa por este cauce abreviado.

En nuestro criterio, vincular de ese modo unanimidad en la adopción del acuerdo de tramitación e improcedencia de enmiendas al articulado constituye

de una naturaleza que justifique la tramitación parlamentaria de un proyecto o de una proposición de ley por el procedimiento de lectura única corresponde al órgano u órganos de la Cámara facultados para ello, sin que, desde la perspectiva de control que nos corresponde de tales decisiones parlamentarias, podamos reemplazar, por respeto a la autonomía de las Cámaras sobre los procedimientos que se desarrollan en su seno, la voluntad o el criterio de oportunidad del órgano u órganos que las han adoptado. En cuanto a la delimitación de los concretos supuestos habilitantes del procedimiento en lectura única, hemos señalado que ni la relevancia o trascendencia constitucional de un texto normativo, ni su repercusión pública, ni su complejidad material, ni, en fin, la existencia de una variedad de criterios técnicos ni políticos sobre el mismo son incompatibles con la utilización de este procedimiento parlamentario, al que no le está vedada materia alguna, incluida la reforma constitucional. Asimismo, hemos referido la simplicidad de la formulación de la iniciativa legislativa no a su especial relevancia o trascendencia en el ordenamiento jurídico, sino a la compresión, sencillez e inteligibilidad de su estructura, contenido y lenguaje».

23 Véase, lo establecido por el Alto Tribunal por primera vez al respecto, en STC $110 / 2019$, de 2 de octubre. 
un error de concepto evidente. Al hacerlo, se está presumiendo que el voto favorable del diputado a ese tipo de tramitación es una renuncia implícita a su derecho de enmienda, abocándolo de ese modo a elegir solo entre las siguientes dos opciones: a) votar favorablemente el acuerdo de tramitación en lectura única y ver suprimido su derecho de enmienda, o b) si pretende presentar enmiendas al articulado, verse obligado a votar en contra de la tramitación en lectura única aunque entienda que concurre alguno de los presupuestos habilitantes y que, por tanto, no es necesario el estudio de la iniciativa en la fase de Comisión.

Sin embargo, puede perfectamente suceder que el diputado entienda que la iniciativa tiene una formulación suficientemente sencilla como para ser debatida y votada - junto con las enmiendas correspondientes - directamente en Pleno y que, además, tenga la intención de, efectivamente, presentar enmiendas al articulado ${ }^{24}$. No son decisiones incompatibles ni excluyentes, por lo que vincular necesariamente la una a la otra supone, precisamente, una limitación del ius in officium del parlamentario que, a nuestro entender, no encuentra apoyatura alguna en la configuración que el reglamento ha realizado de este derecho fundamental en uso de la habilitación constitucional establecida ${ }^{25}$.

Consecuentemente, y en segundo lugar, afirma también el Tribunal Constitucional en este pronunciamiento que, por el contrario, si el acuerdo de tramitación se adopta por mayoría simple y no se permite la presentación de enmiendas, se incurriría en todo caso en vulneración del art. 23.2 CE de la minoría parlamentaria que no votó a favor de tal acuerdo de tramitación en lectura única ${ }^{26}$. Argumento que tampoco compartimos, puesto que: a) si el

24 Véase, Aláez (2018: 21 y ss.).

25 Véase, más al respecto, en Biglino Campos (1993: 53 y ss.); García Roca (1999: 24 y ss.); Garrorena (2011: 141); Jiménez (1997: 412).

26 STC 139/2017, de 29 de noviembre: «Si el tenor y el sentido del silencio del artículo 135 RPC [que ya no exige unanimidad en la decisión del Pleno] en torno al trámite de enmiendas en el procedimiento de lectura única implicasen, como sostiene el Abogado del Estado, y a los efectos que a este proceso constitucional interesan, la exclusión de la posibilidad de presentar enmiendas a las proposiciones de ley tramitadas por dicho procedimiento, resultaría evidente que el precepto impugnado, como se razona a continuación, vulneraría el artículo 23.2 CE. En efecto, si ese fuese el significado de aquel silencio, no se trataría entonces de que la Cámara en el ejercicio de su autonomía parlamentaria hubiera limitado el ejercicio del derecho de enmienda en esta especialidad del procedimiento legislativo. [...] una hipotética exclusión de la fase de enmiendas en la tramitación de las proposiciones de ley por el procedimiento de lectura única restringiría notablemente las facultades de participación de las 
Pleno ha apreciado la concurrencia del primero de los presupuestos habilitantes - la naturaleza pactada de la norma-, lo que procede es precisamente no abrir trámite de enmienda, tal y como admitió el propio Tribunal en STC 27/2000, de 31 de enero, y b) por el contrario, si estamos ante un supuesto de iniciativa legislativa de formulación sencilla, que exista o no lesión efectiva y relevante del derecho fundamental del art. 23.2 CE dependerá de las concretas circunstancias del caso, esto es, que la pretensión de participación en la decisión legislativa a través del trámite de enmiendas al articulado no haya podido vehicularse de otro modo suficiente en el procedimiento y que, además, esa limitación ilegítima del derecho del diputado haya sido determinante para la formación de la voluntad de la Cámara, como el mismo Tribunal había venido afirmando reiteradamente hasta la fecha.

Por último, añade el Tribunal Constitucional en los párrafos finales de la sentencia que, en todo caso, con independencia de cómo se entienda el alcance de los presupuestos habilitantes de la lectura única, incluso si su interpretación es más restrictiva que la propuesta por su jurisprudencia, ni la naturaleza, ni la simplicidad de formulación de la iniciativa legislativa pueden justificar por sí mismas la supresión del derecho de enmienda.

Así, se afirma en la sentencia que "cualquiera que sea la interpretación que los órganos competentes de la Cámara efectúen de los supuestos habilitantes de este procedimiento parlamentario, incluso si se inclinan por un entendimiento más restrictivo del que ha admitido la doctrina de este Tribunal, ni la naturaleza de la iniciativa legislativa, ni la simplicidad de su formulación pueden justificar por sí mismas la absoluta privación del derecho de enmienda de los diputados y de los grupos parlamentarios en el procedimiento de lectura única. [...] La exclusión del derecho de enmienda en atención a la naturaleza o simplicidad de formulación de la iniciativa legislativa supone, en definitiva, un menoscabo constitucionalmente inaceptable del principio democrático y del pluralismo político que deben presidir e informar el procedimiento legislativo, también el de lectura única». En nuestro criterio, si esa interpretación más restrictiva de los presupuestos habilitantes y, en concreto, del primero de ellos — la naturaleza de la iniciativa-, en la que los

minorías en el procedimiento legislativo, hasta el punto de poder resultar afectada la igualdad que exige, en cuanto a la posición de unos representantes y otros, el artículo 23.2 CE. En efecto, los miembros del grupo proponente de la iniciativa legislativa, con la anuencia de la mayoría que ha adoptado el acuerdo de tramitación por el procedimiento de lectura única, habrían podido determinar a su libre criterio, barajando cualesquiera opciones, el contenido del texto de la iniciativa legislativa sobre el que, sin embargo, los miembros de las minorías no tendrían más opción que la del rechazo o aceptación en su conjunto, y sin matices, de la iniciativa propuesta». 
órganos de la Cámara identificaran naturaleza que lo aconseje con condición de norma pactada, cabría privación del derecho de enmienda de los parlamentarios, en los términos de la citada STC 27/2000, de 31 de enero.

\section{UNA PROPUESTA DE MODIFICACIÓN DE LOS USOS PARLAMENTARIOS}

El momento procesal de presentación de enmiendas no viene establecido por el reglamento de la Cámara cuando el proceso legislativo implementado es el de lectura única. En ausencia de norma expresa, es un uso parlamentario consolidado que la apertura del plazo de presentación de enmiendas tenga lugar una vez tomada en consideración la iniciativa e inmediatamente después de que el Pleno adopte la decisión de tramitarla por el procedimiento abreviado en lectura única. Entendemos que una sencilla modificación de facto de los tiempos en los que tienen lugar la toma de tales decisiones favorecería una protección más eficaz de los derechos derivados del ius in officium aquí descritos ${ }^{27}$ :

En caso de que la tramitación en lectura única venga justificada por la naturaleza pactada de la iniciativa — por ejemplo, la Ley Orgánica de Reintegración y Amejoramiento del Régimen Foral de Navarra - evidentemente lo que procede es no abrir trámite de presentación de enmiendas puesto que la Cámara debe emitir un voto de ratificación sobre el texto ya cerrado; pero si estamos ante la segunda de las circunstancias que permiten la tramitación de la iniciativa en lectura única — simplicidad de su formulación-, sería muy conveniente que las enmiendas se pudieran presentar tras la toma en consideración y antes de la adopción del acuerdo de tramitación de la iniciativa por este cauce abreviado.

De este modo, la Mesa, la Junta de Portavoces y el Pleno dispondrían tanto del texto original como del texto de las enmiendas propuestas antes de calibrar si el objeto que discutir en sede parlamentaria - que no es solo la proposición o proyecto, sino que es ese documento más el relativo al de las correspondientes enmiendas - posee una condición suficientemente sencilla como

27 Según doctrina del Tribunal Constitucional, los usos parlamentarios y su observación "pueden llegar a ser dignos de consideración para el debido respeto de los derechos de los representantes», pero carentes de «relieve constitucional» en el resto de casos (STC 110/2019, de 2 de octubre). En este supuesto, se propone la modificación de los usos parlamentarios hasta la fecha consolidados precisamente para una mejor y mayor garantía de los derechos que integran el ius in officium de los parlamentarios. 
para poder ser sustanciado directamente ante el Pleno sin pasar por el estudio en fase de comisión.

Aunque resulta poco probable, no es imposible que una iniciativa legislativa que a priori presentara una redacción sencilla pudiera convertirse, como consecuencia de la interposición de numerosas y complejas enmiendas, en una iniciativa necesitada de análisis previo en comisión - fase que habríamos omitido si previamente se hubiera optado por su tramitación en lectura única-.

Adelantando, pues, el momento de la presentación de enmiendas, no solo pondríamos a los órganos rectores de las Cámaras en mejor disposición para decidir qué tipo de tramitación legislativa resulta más pertinente, sino que, además, de este modo se evitarían la mayor parte de las eventuales vulneraciones tanto del derecho al procedimiento adecuado como del derecho a la enmienda que aquí hemos descrito.

\section{Bibliografía}

Aláez Corral, B. (2018). Los limites materiales a la reforma de la Constitución española de 1978. Madrid: Centro de Estudios Políticos y Constitucionales.

Alexy, R. (2014). Teoría de los derechos fundamentales. Madrid: Centro de Estudios Políticos y Constitucionales.

Arce Janáriz, A. (1996). El trámite de admisión de los procedimientos parlamentarios en la jurisprudencia constitucional. Revista Española de Derecho Constitucional, 46, 207-238.

Arruego Rodríguez, G. (2005). Representación politica y derecho fundamental. Madrid: Centro de Estudios Políticos y Constitucionales.

Biglino Campos, P. (1993). Las facultades de los parlamentarios, ison derechos fundamentales? Revista de las Cortes Generales, 30, 53-100. Disponible en: https://doi.org/10.33426/ $\mathrm{rcg} / 1993 / 0 / 424$.

Cobreros Mendazona, E. (1991). El status parlamentario como derecho fundamental garantizado por el art. 23.2 de la Constitución. En AA.VV. Estudios sobre la Constitución Española. Homenaje al Profesor Eduardo García de Enterría (pp. 2125-2184). Madrid: Civitas.

Fernández Cańueto, D. (2018). Las consecuencias de la reforma del art. 135.2 del Reglamento del Parlamento de Cataluña para aprobar la Ley de referéndum y la de transitoriedad jurídica: suspensión y STC 139/2017. Revista Vasca de Administración Pública, 111, 207-246.

Fossas Espadaler, E. (1993). El derecho de acceso a los cargos públicos. Madrid: Tecnos.

García Roca, J. (1999). Cargos públicos representativos. Un estudio del art. 23.2 de la Constitución. Pamplona: Aranzadi.

- (2014). Pautas para una reforma constitucional. Madrid: Aranzadi.

García-Escudero Márquez, P. (2007). El procedimiento agravado de reforma de la Constitución de 1978. Madrid: Centro de Estudios Políticos y Constitucionales. Disponible en: https://doi.org/10.5944/rdp.71-72.2008.9043.

- (2009). La reforma del artículos 135: ¿̨son suficientes trece días para la tramitación parlamentaria de una reforma constitucional. Cuadernos de Derecho Público, 38, 79-88. (2011). Manual de técnica legislativa. Madrid: Civitas. 
- (2012). Los límites al derecho de enmienda en la reforma constitucional y la nueva doctrina del Tribunal Constitucional sobre las enmiendas a iniciativas legislativas. Revista Cuadernos Manuel Giménez Abad, 3, 58-67.

Garrorena Morales, A. (2011). Voz «Mandato representativo». En M. Aragón Reyes (dir.). Temas Básicos de Derecho Constitucional. Tomo II. Organización del Estado (pp.141 y ss.). Madrid: Civitas.

Gómez Lugo, Y. (2007). La tramitación legislativa en lectura única. InDret. Revista para el Análisis del Derecho, 4, 1-16.

- (2009). El derecho a tramitar las iniciativas por el procedimiento adecuado. InDret: Revista para el Análisis del Derecho, 4, 1-21.

— (2019). La tramitación de la reforma constitucional mediante procedimientos legislativos abreviados: un problema de límites procedimentales. Teoría y Realidad Constitucional, 43, 389-419. Disponible en: https://doi.org/10.5944/trc.43.2019.24432.

Jiménez Campo, J. (1997). Sobre los derechos fundamentales de los parlamentarios. En AA.VV. Estudios de Derecho Constitucional y Ciencia Política. Homenaje al Profesor Fernández-Carvajal (pp. 219-232). Murcia: Universidad de Murcia.

Pulido Quecedo, M. (1992). El acceso a los cargos y funciones públicas. Un estudio del art. 23.2 de la Constitución. Madrid: Civitas.

Schmitt, C. (2008). Los fundamentos histórico-espirituales del parlamentarismo en la situación actual. Madrid: Tecnos.

Torres Muro, I. (1998). Los derechos de los parlamentarios. Revista de Derecho Politico, 44, 257-281. 